\title{
Innovative potential of "digital methodology" in the training of personnel of nuclear industry enterprises
}

\author{
Oksana Filatova ${ }^{1, *}$, Galina Khoroshavina $^{2}$, Maksim Gordeev ${ }^{1}$, SergeyChibirev $^{3}$, and \\ Vladimir Pozdnyakov ${ }^{3}$ \\ ${ }^{1}$ Rosatom Technical Academy, Kurchatov str., 21, Obninsk, Kaluga region, 249031, Russia \\ ${ }^{2}$ Bauman Moscow State Technical University (National Research University), $2{ }^{\text {nd }}$ Baumanskaya str., \\ 5, Moscow, 105005, Russia \\ ${ }^{3}$ Federal State Budget Educational Institution of Additional Professional Education "Institute for the \\ Development of Additional Professional Education", $1{ }^{\text {st }}$ Shchipkovskiy lane, 20, Moscow, 115093 , \\ Russia
}

\begin{abstract}
The article considers the first stage of designing diversification of professional retraining programs for employees of the nuclear industry in the conditions of digital transformation of the industry. The article justifies the new digital approaches to personnel training. At the project development stage, the general methodological foundations of digital disciplines in knowledge production were established in the form of a "digital methodology," the core of which is the knowledge paradigm of technoscience. The potential of "digital methodology" leads to the development of the mental, social, organizational resources of workers. The worldview platform of the project made it possible to formulate guidelines for the formation of competencies in the diversification of the professional retraining program: the development of critical and analytical thinking, technological literacy, personal growth, communicative initiative, and social responsibility. The authors note that the recognition of the methodological reflection of digital technologies is presented in the publications of researchers in various scientific fields, while the practice of foreign research is more advanced in the development of a quantitative assessment of qualitative indicators, and the domestic tradition is focused on the cognitive aspect of digitalization. But the convergence of approaches is manifested in the diversity of digital learning practices.
\end{abstract}

\section{Introduction}

The problem of updating the retraining and advanced training programs of industry specialists in corporate organizations of additional professional education is set by the guidelines of the large-scale digital transformation of the Russian economy, as well as the strategy of the industry, due to the development of new directions in the development of the nuclear industry - nuclear medicine, wind energy, composite materials, digital products and environmental projects. Fundamental changes in science and education due to the spread of

*Corresponding author: OLFilatova@rosatomtech.ru 
digital technologies objectify the need to understand the general methodological foundations of digital ways of knowing, forming the issue of a new field of knowledge of "digital methodology." The request for methodological reflection of digital technologies in training has resonated in the form of theory and methodology of informatization of education (I.V. Robert, N. V. Dneprovskaya, V.P. Tikhomirov, and others) [1-3].

At the same time, the "digital transition" revealed a shortage of competencies in the field of soft skills (business thinking, self-organization, communications), unlike hard skills, ownership of computers and software applications. Statistics for higher education also indicate a lag in the formation of skills in working with information (55\%) from skills in working with digital equipment (66\%).

Concerns about the problem are contained in the EU JRC Report: «Traditional education systems are not best equipped to cope with the changing nature of learning, the changing demands on learners and their competences, and the need for new ways of teaching and managing complexities. Numerous studies find that system-wide educational innovation is notoriously difficult to achieve» [4]. The practice of professional education revealed the problem of reducing the role of mental activity, cognitive interest, personal development in the profession, "half-life of competence," which contradicts the tasks of an innovative breakthrough in the digital economy.

The objective of this article is to analyze the potential of "digital methodology" in forming the readiness of participants in professional retraining programs to innovate the digitalization of the industry. Achieving the goal predetermined the raising of following questions:

- Is there a need for a general methodological justification of digital disciplines and digital technologies in science and education?

- What (and how) do the resources of the potential of "digital methodology" motivate the innovative direction of learning?

- What are the advantages of additional education programs in shaping readiness for innovation?

\section{Materials and Methods}

The issues of methodology of digital methods and digital technologies are fruitfully developed in the field of humanities (Digital Humanities), epistemology and philosophy (Epistemology and Philosophy of Science), social sciences, including pedagogical ones. The need for methodological reflection of digital methods is covered in the publications "Computers and Education", "Teaching and Teacher Education", "The Digital Scholar: Philosopher's Lab". The concept of "digital methodology," as Russian scientists note, is in demand, applied and gives results in studies of the phenomenon of digital transformation, but for the Russian philosophical tradition it is a new and sometimes marginal phenomenon, although more accurate knowledge naturally requires improvement of cognitive activity. The interpretation of "digital transition," as a simple replacement of analog systems with digital devices using digital technologies, for the period of technoscience seems insufficient.

Although in publications the debating nature of the conceptual apparatus of digitalization is not denied, technological emphasis prevails. Meanwhile, the development of modern science of the "post-classical type" and the "breakthrough" nature of the formation of the digital economy led to the overcoming of methodological dogmatism, when the semantic aspects of the processes of growth of scientific knowledge were supplanted to the periphery of research interest.

A new understanding of knowledge in the context of the postnonclassical paradigm of science, as technoscience, in the integration and convergence of technologies, the 
complexity of multidimensional self-developing systems, the nonlinearity of physical reality, opened the scope for heuristic design of innovations. Interdisciplinary interaction created a diachronic and emergent moment of movement towards new forms of organization of knowledge. In addition to ideas about the importance of knowledge in the digital economy, the actualization of training programs was accompanied by the testing of productive ideas of the concepts of "smart education", STEM education (Science + Technology + Engineering + Mathematics), "blended learning" (a combination of traditional and e-learning).

The systematization and synthesis of publications on digital learning made it possible to clarify the semantic content of the concept of "digital methodology" as the general methodological foundations of digital disciplines in creating new knowledge and formulate a worldview platform for diversifying professional retraining programs of Rosatom Technical Academy. The empirical data of the study were formed by observation methods, surveys and questionnaires of program participants, teachers, and instructors. The synthesis of the results was carried out by logical methods of analysis and synthesis, comparison, extrapolation, systematization and ordering of information of scientific publications. The analysis of the inclusion of group participants in the new working conditions was carried out by adapting the R. Hackman-G. Oldham methodology.

\section{Results}

To understand the readiness of retraining programs applicants for innovation, the general methodological foundations of knowledge production in the digital age were clarified: - the knowledge paradigm of technoscience; - S. Fuller's "algorithmic deism", when "a person and a computer act as alternative platforms for realizing "abilities "or "functions "that do not depend on material differences between platforms"; - ideas of scientists about the "digital methodology," which "opens up the fields of thinking" for analyzing the conditions of production and sociotechnical design of reality; - knowledge-intensive potential of industry enterprises, new products creation, new technologies, new forms of production organization.

The strategic guidelines of the industry and methodological approaches to changing the role of knowledge in science and education, laid down in the basis of the "digital methodology," have led to the development of a project to diversify retraining and advanced training programs for Rosatom Technical Academy personnel. Diversification was considered as an organizational and pedagogical complex of updating the resources of the digital methodology in the reconfiguration of the training process from memorizing and reproducing information towards motivated intellectual development, initiative behavior, and the mental readiness of the employee for innovation. The arsenal of pedagogical means of diversifying retraining programs in the light of the paradigm of knowledge of digital methodology has been tested by the practice of vocational education: this is the modularity of training programs, variability, designability, interdisciplinary interconnectedness, flexibility of educational technologies. The study of the methodological basis of digital disciplines in the design of changes in personnel retraining programs was based on the Unified Digital Strategy (UDS) of Rosatom, approved in 2018. The Strategy identified three key areas:

- participation in the digitalization of Russia as the Competence Center of the Federal Project "Digital Technologies" of the National Program "DE";

- creation of digital products, high-tech solutions for nuclear energy and other industries;

- internal digitalization, a single digital architecture for the industry based on its own IT solutions and a clear orientation towards economic effect. 
In 2019, the State Corporation formed a digitalization unit to control the digital transformation of the industry.

To solve the problem of optimizing the learning process based on the "digital methodology," factors were identified and grouped that stimulate the innovative orientation of specialists in the work (table 1).

Table 1. Resources to innovate the potential of "digital methodology"

\begin{tabular}{|c|c|}
\hline $\begin{array}{l}\text { Resources of } \\
\text { capacity of DM }\end{array}$ & $\begin{array}{l}\text { Parameters of changes in retraining and advanced training } \\
\text { programs }\end{array}$ \\
\hline $\begin{array}{l}\text { Mental } \\
\text { characteristics: } \\
-\quad \text { readiness for } \\
\text { innovation and } \\
\text { self-development - } \\
\text { active position of } \\
\text { the training } \\
\text { participant } \\
\text { (subject } \\
\text { cognition) of } \\
\text { - value-meaning } \\
\text { resources } \\
\text { "numbers"; }\end{array}$ & $\begin{array}{l}\text { Development of mental abilities: } \\
\text { - scientific thinking (analysis, hypothesis promotion, synthesis, } \\
\text { logical experiment, goal setting, task determination); } \\
\text { - critical thinking (justification of evidence of rational and } \\
\text { optimal decisions, evaluation of information, reasoning skills, } \\
\text { argumentation, justification, presentation of ideas); } \\
\text { - new forms of thinking: problem setting, dispositive } \\
\text { construction, programming, design, configuration; } \\
\text { - acceptance of alternative knowledge, pluralism of methods of } \\
\text { knowledge, freedom with regard to scientific traditions, } \\
\text { convergence and integration of concepts of different fields of } \\
\text { knowledge in the creation of new knowledge; } \\
\text { - abilities of collection, selection of information, the choice of } \\
\text { priorities in aggregation of resources and platforms of interaction; } \\
\text { - orientation in complex multidimensional objects and non-linear } \\
\text { processes, analytically and structurally; project activities; } \\
\text { - skills of working with large information arrays, skills of } \\
\text { processing large data flows; }\end{array}$ \\
\hline $\begin{array}{l}\text { Social and } \\
\text { communicative } \\
\text { capabilities of the } \\
\text { digital } \\
\text { environment }\end{array}$ & $\begin{array}{l}\text { Transformation is a process of transition from a linear subject - } \\
\text { object communication in classical learning to a communicative } \\
\text { action: } \\
\text { - interdisciplinary interaction in knowledge production and } \\
\text { training; } \\
\text { - "soft links" of electronic resources, forums, webinars, online } \\
\text { communities, networking (networking) virtual space for } \\
\text { discussion of new forms of knowledge creation and transfer; } \\
\text { - Changing the nature of communication - informal integration of } \\
\text { participants around a topical issue; } \\
\text { - teamwork skills based on distributed systems, } \\
\text { the ability to join forces in a team to create new knowledge; }\end{array}$ \\
\hline $\begin{array}{l}\text { Resources of } \\
\text { organizational } \\
\text { impact of the } \\
\text { digital educational } \\
\text { environment }\end{array}$ & $\begin{array}{l}\text { Common information space of the enterprise production } \\
\text { environment: } \\
\text { - digital educational environment: a platform of organizational } \\
\text { and technical measures; verified educational content and services } \\
\text { - designing a distributed learning environment, including the } \\
\text { territory of RTA, training on remote access, continuous education } \\
\text { mode; the Internet, web 2.0, various types of Social Media; Data } \\
\text { Mining technologies; VR and AR technologies (virtual and } \\
\text { augmented reality); } \\
\text { - individual educational trajectories with content creation for each } \\
\text { listener - flexible educational trajectories; } \\
\text { - technological solutions for training: smart boards, smart }\end{array}$ \\
\hline
\end{tabular}




\begin{tabular}{|l|l|}
\hline & textbooks, smart projectors, educational content software; \\
Massive online courses; immersive education (immersion); \\
adapting the devices to the needs during their operation; \\
- fast feedback technologies; mobile offices and continuity of \\
communication with partners and consumers; databases of \\
business and scientific information, with minimization of access \\
links to information.
\end{tabular}

Digital transformation causes reconsideration of working processes, models of management, communications, continuous changes that assumes efficiency of data exchange, unification of concepts and terms on all chains of business processes, increase of a role of "useful knowledge", experience of optimal solutions acceptance along with regulations of actions. Experts estimate that the corporation will need about 2 million new engineering personnel in the next quarter century. These are specialists "in existing IT systems, for example, ERP, and in those technologies that are only being implemented today: the Internet of Things, 3D printing, big data. The market of specialists in cybersecurity of the nuclear industry and important infrastructures is forming" [5].

An obvious example is the implementation of the Rosatom State Corporation's innovative project to create the Akademik Lomonosov floating power unit. At the beginning of 2020 in the register of digital developments of Rosatom there are 149 developments. Many innovation products have been successfully brought to the market and are in demand by enterprises of various industries. Among the most notable products are Logos, Wave, Prism 2.0, (MCUD) Pilot, Multi-D digital platform and many others [6].

Diversification of retraining programs of Rosatom Technical Academy is aimed at forming the readiness of workers to innovate digital transformation. The employee's readiness for innovation can be studied based on the employee's motivational potential. A high indicator shows inclusion in the new format of work, activity of the employee, his identification with the goals of the corporation. The methodology of R. Hackman and G. Oldham - job diagnostic survey (JDS) - can be adapted for quantitative evaluation (J. Richard Hackman, Work Design, Santa Monica, Calif., 1977).

Table 2. From materials of expert work

\begin{tabular}{|c|c|c|}
\hline Criterion & $\begin{array}{ll}\text { Group } & \text { of } \\
\text { participants } & \text { in } \\
\text { retraining } & \\
\text { programs } & \end{array}$ & $\begin{array}{l}\text { Employees } \\
\text { unoccupied in } \\
\text { retraining } \\
\text { program }\end{array}$ \\
\hline Variety & 5,6 & 4,3 \\
\hline Completeness & 4,7 & 5,0 \\
\hline Importance & 5,8 & 4,1 \\
\hline Autonomy & 5,4 & 3,4 \\
\hline Feedback & 5,2 & 4,1 \\
\hline Motivationalpotential & 156 & 75,8 \\
\hline
\end{tabular}

A survey of one of the groups of program participants (table 2) shows their readiness for new working conditions is almost 2 times higher. A complete analysis with the justification of the validity of the assessment requires long-term observations, refinement of the toolkit in the form of a questionnaire, and representativeness of the sample. Preliminary results show that program diversification optimizes the process of professional retraining, meeting the needs of the industry for next-generation engineers during the digital transformation phase. 


\section{Discussions}

On the first question, the understanding of "digital methodology" as the methodological basis of digital disciplines in creating new knowledge, and, therefore, the request for methodological reflection of digital technologies, was confirmed in the publications of researchers from different fields of knowledge. "The education system cannot and should not be value-neutral: if it does not form constructive value-meaning and sociocultural attitudes, the vacuum is filled with spontaneously emerging life-threatening, often destructive orientations. Methodological foundations of new pedagogy in connection with ICT ("integrative pedagogy") determine the intellectual nature of the learning process [7]. "Reflexive awareness is also at the foundation of methodological perspectives in qualitative social science research,... the same that should be reflected in digital humanities work, "as the focus and increasing effectiveness of digital information systems... coincided with a growing interest in new topics and methods of research, representatives of the humanities noted (Tanya E. Clement, Daniel Carter).

The development of "digital methodology" is characterized by publications of a criticalanalytical and design-constructivist nature. In the first case, the processes of thinking, cognitive activity in connection with the critical reflection of new ways of cognition are investigated. In the second case, the methodology justifies the creation of a new subject area, new concepts and objects, the birth of a new discipline, digital rhetoric, mobile learning (m-learning). Teachers offer to synthesize disciplines, «to integrate knowledge from different subject areas, to develop algorithms and software, instrumental technologies for creating a series of electronic textbooks for teaching synthetic disciplines based on hypertext access to a data bank make it possible to carry out the teaching of synthetic disciplines, reaching a new standard of quality» [8].

Russian scientists consider the understanding of methodology in the focus of the paradigm of cognition, and the tools (methods) that are developed in various disciplinary fields, at various levels of scientific search, are a resource for conceptualizing the foundations of the cognitive process, new theoretical and cognitive guidelines of which mean the principles of organizing the cognitive process associated with the adoption (mastering) of the postnonclassical ideal of rationality.

This approach is shared by a number of foreign researchers: "Tool criticism paves the way to move from digital methods to" digital methodology" [9]. And on this path of digital disciplines, it is important to find an ethical consensus between the "under-definition" of philosophical and special scientific subjects and methods, and knowledge management. Methodological considerations are of particular importance in the formation of new disciplines, for example, digital rhetoric, integrative teaching, while the methodology is considered an example of global operations, creating a general picture, and theory. «The research is based on the methodology of institutional theory», Russian scientists believe, analyzing the formation of "network economy" [10].

The epistemological approach to digital technologies is supported in didactics: "Until these methodological perspectives are not brought together, digital resources will play a merely playful and motivational role, and will not develop a truly critical approach that instills in students the ability to evaluate digital information" [11]. Methodological reflection of digital disciplines is formed at the level of interdisciplinary interaction, coordination of ideas of traditional and new, enriching the structure of rational and cognitive activity in science and education. «The definition of education informatization as a process and a field of pedagogical knowledge has been formulated. The main directions of the development of education informatization have been considered. Methodological approaches to the forecast of the development of scientific and practical zones occurring in traditional sciences and in interdisciplinary research» [12]. 
The conclusions on the second issue of the introduction are based on the recognition of the objective nature of designing digital methods in a rational and reflexive understanding of new educational opportunities, which is due to the laws of knowledge formation in technoscience. The publications emphasize that technologies open the didactic prospect of enriching the content of training, mastering the ways of solving problems, using digital research methods in the formation of knowledge [13]. The development of online collaborative learning theory (OCL), scientists propose using a constructivist approach and using a number of methodologies that are more precisely defined as teaching methods expositive, demonstrative, interactive, and practical [14].

This approach of quantitative analysis of the qualitative assessments design attracts Russian scientists: «It is proven that it helps to carry out the procedure of assessing the level of innovative potential using a set of methods of taxonomic analysis - classic, modified, and unified ones» [15]. In Knowledge Management «the scientific novelty consists of the proposed the indicators and evaluation tool for identification the KM» [16]. The methodological aspect, as a shift in the educational paradigm that combines learning with the network connection of education, is manifested by an example of "participative pedagogy". In the dissertation of K. de Groof Kaiser (2019), multimedia materials, project activities, a variety of diagnostic and evaluation tools are shown in the development of "integrating pedagogy". The advantages of mobile training are analyzed [17]. However, Russian teachers are more cautious about the consequences of digital learning, noting a decrease in the intellectual level, namely, the loss of self-writing skills, the creation of drawings that are replaced by the skills of compilation, the use of ready-made forms, layouts, images, the catastrophic loss of literacy and computing skills, and therefore the loss of creative abilities, which is natural to consider as a barrier to innovative development. The constructivist approach of foreign practice attracts attention, but convinces the importance of methodological justification of the cognitive potential of digital technologies. The conclusion on the advantages of additional vocational education is based on its legitimacy to make changes to retraining programs, in accordance with the requests of the employer.

Foreign research presents two aspects of diversification: - knowledge production, that is, research and development ( $R \& D$ ); - the use of knowledge in production, namely, the development of instrumental and operational knowledge. The development of skills and competencies is emphasized more than understanding and thinking, which is expressed by the concept from "knowledge as knowing' to knowledge as operational." At the same time, technological achievements are associated with the work of highly qualified professionals. Russian scientists emphasize a gradual transition to forming the theoretical and practical models for dealing with them through trans-disciplinary methodology on a pluralistic approach [18]. The practice of Diversity training programs, which focuses on the performance of employees, their involvement in work, has become widespread.

\section{Conclusions}

The study of the potential of "digital methodology" in training was carried out by designing the diversification of training programs and the focus of training on the formation of the readiness of program participants for innovations caused by the digitalization of the industry. During the study, it was established:

1. Digital transformation is a logical stage in the development of technoscience, the knowledge paradigm of which actualizes new approaches to training, the formation of employees' readiness for innovations of the "digital transition".

2. Methodological justification of digital technology resources in the production of new knowledge is advisable to consider a "digital methodology," a new emerging field of 
knowledge, the potential of which focuses on the development of the mental, social, organizational resources of the employee, which manifest his readiness for innovation and self-development.

3. A logical analysis of publications showed the recognition of the methodological reflection of digital technologies in the form of a movement towards "digital methodology" of researchers from different fields of knowledge, the development of which is carried out by different approaches: critical-analytical and design-constructivist nature.

4. The design of diversification of retraining programs corresponded to the logic of the knowledge paradigm and digital production strategy in the training of engineers with new competencies (critical thinking, intellectual analysis, technological literacy, selfdevelopment, communicative interaction, social responsibility).

5. The development of a quantitative assessment of qualitative changes in retraining programs based on the methodology of R. Hackman and G. Oldham showed prospects already at the stage of field testing.

6. The benefits of additional education programs are determined by less reliance on State standards and the possibility of more flexible modular variable offerings.

7. The emphasis on the cognitive dimension of digitalization has limited the scope of the presentation of other parties to the diversification project, namely means and methods of learning in the knowledge paradigm, directions and forms of diversification of additional education.

In the formation of "digital methodology," as a new field of knowledge, the moment of overcoming objectivity and the transition to reflection of the cognitive capabilities of a set of digital methods and means is not completed. It can be assumed that the unity of the diversity of digital learning will be achieved by a variety of digital practices, on the basis of which principles, concepts, "laws" of thinking will be developed, which constitutes the discipline of "digital methodology."

\section{References}

1. I. V. Robert, SHS Web of Conferences, 55, 03014, ICPSE (2018) https://doi:10.1051/shsconf/20185503014

2. I. V. Robert, Proceedings (ICEDER 2018), 288, 36-40 (2018) https://doi:10.2991/iceder-18.2018.8

3. N. V. Dneprovskaya, N. V. Komleva, A. I. Urintsov, Proceedings AIMEE 2018, 641650 (2019) DOI: 10.1007/978-3-030-12082-5_58

4. J. Conrads, M. Rasmussen, N. Winters, A. Geniet, L. Langer, Digital Education Policies in Europe, JRC Science for Policy Report, Luxembourg, 6 - 11 (2017) https://doi:10.2760/462941,JRC109311

5. V. Tormasov, Atomic Expert, corporative journal, 2 - 3 (2019) URL: http://atomicexpert.com/digitalization (Last accessed 12.04.2020)

6. E. Katkova, Atomic Expert, corporative journal, 6, 56 - 60 (2020) URL: http://atomicexpert.com/ (Last accessed 14.06.2020)

7. I. Robert, S. Neustroev, M. Goncharov, Proceedings ICEDER, 288, 8 (2018) URL:http://www.atlantispress.com/php/pub.php?publication=iceder-18 (Last accessed 14.06.2020)

8. S. Khachaturova, T. Shikhnabieva, A. Arinushkina, Proceedings ICEDER 2018, 288, 21 - 25 (2018) URL: http://www.proceedings.com (Last accessed 14.06.2020)

9. K. van Es, M. Wieringa, M. Tobias Schafer, WS.2 Proceedings, 24 - 27 (2018) https://doi.org/10.1145/3240431.3240436 
10. E. Ustyuzhanina, S. Evsukov, I. Komarova, European Research Studies Journal, v. XXI, 3, 77-89 (2018) https://DOI:10.35808/ersj/1045

11. P. Miralles-Martinez, C. J. Gomez-Carrasco, V.-B Arias-Gonzales, O. Fontal-Merillas, Comunicar, 61, 45-56 (2019) https://doi.org/10.3916/C61-2019-04

12. I. V. Robert, et al., Revista Espacios, 38(40), $32 \quad$ (2017) URL:https://www.revistaespacios.com/a17v38n40/a17v38n40p32.pdf (Last accessed 16.06.2020)

13. M. Claro, A. Salinas, T. Cabello-Hutt, E. San Martin, D. D. Preiss, S. Valenzuela, I. Jara, Computers \& Education, 121, 162-174 (2018) https://doi.org/10.1016/j.compedu.2018.03.001

14. M. J. Sousa, R. Cruz, J. Miguel Martins, 9th International Conference on Education and New Learning Technologies, Conference Paper, Barcelona, 5185 (2017) https://DOI:10.21125/edulearn.2017.2158

15. E. Y. Nikolskaya, et. al., RevistaEspacios, 39(27), $30 \quad$ (2018) https://www.revistaespacios.com/a18v39n27/in183927.html (Last accessed 14.06.2020)

16. N. V. Dneprovskaya, A. I. Urintsov, N. V. Komleva, Proceedings, (ECKM 2018), Padua, 1, 182-189 (2018) URL: http://toc.proceedings.com/41358webtoc.pdf

17. M. A. Camilleri, A. C. Camilleri, 13th International Conference on Mobile Learning, Proceedings, 42 - 48 (2017) https://files.eric.ed.gov/fulltext/ED579190.pdf (Last accessed 19.06.2020)

18. I. V. Mkrtumova, L.I. Kononova, M. V. Vdovina, E. G. Studenova, S. A. Potutkova, $\begin{array}{llll}\text { Italian Sociological } & \text { Review, } & \text { 9(1), } & 119-130\end{array}$ http://dx.doi.org/10.13136/isr.v9i1.231 